\title{
NON-LINEAR DYNAMIC ANALYSIS AND DESIGN CONCEPTS FOR RC BEAMS UNDER IMPULSIVE LOADS
}

\author{
Ayaho Miyamoto*, Michael E. King* and Manabu Fujii*
}

\begin{abstract}
SUMMARY
The behaviour of reinforced concrete ( $R C$ ) beams under impulsive loading was studied in both the elastic and elasto-plastic regions by use of the finite element analysis. The calculations were then compared with experimental results for verification. Various impact force-time characteristics, beam geometries, material strengths and steel fibre contents were altered to study the effects on items such as behaviour in the critical region, energy absorption at failure and local deformation. These factors were then used to draft out a guideline on design concepts necessary for RC beams under impulsive loads.
\end{abstract}

\begin{abstract}
Editor's Note: This paper was first published in the Proceedings of the 1988 Pacific Concrete Conference and is reprinted with the permission of the Cement and Concrete Association of New Zealand and the New Zealand Concrete Society.
\end{abstract}

\section{INTRODUCTION}

In recent years there has been a growing use of concrete structures in various fields. especially under severe loading conditions such as in offshore environments and even possibly in space. One such example is in the case of impulsive loading. At present, the dynamic behaviour of structures under impulsive loading is yet to be fully understood. Various studies on the dynamic behaviour of soft impacts and evaluation of impact resistance based on experiments have been carried out $[3,5-10]$. The lack of precision in measurements till lately and also the vagueness of the definition of impact resistance has rendered quantitative studies practically impossible. The main aim of this paper is to make a quantitative study on RC beam behaviour under impulsive

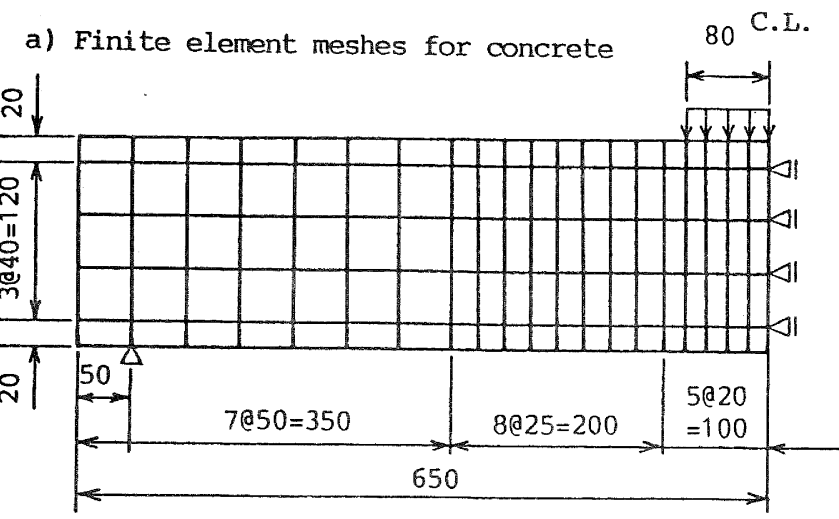

loads, provide a suitable definition for impact resistance and finally propose some design concepts.

An analytical study of RC beams under impulsive loads was carried out using the non-linear dynamic finite element method. Material nonlinearity was considered in the modelling of concrete and reinforcement. The Newmark- $\beta$ method was employed for solving the equation of motion during each time interval. The calculations for a given load-time function were then verified by results from experiments until failure. It was found that quite accurate results can be obtained from this analysis. Behaviour in the critical region, energy absorption at failure, local deformation etc. were compared under different conditions to examine the degree of their contribution to

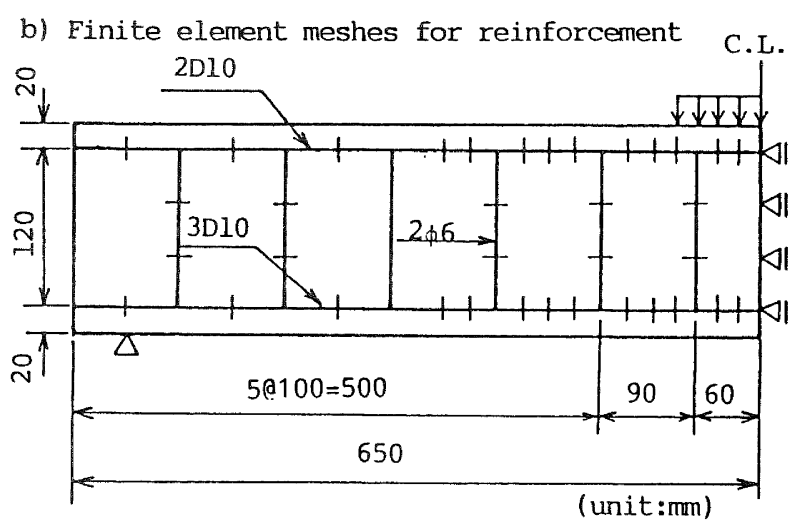

FIGURE 1 : FINITE ELEMENT MESHES FOR RC BEAMS

\footnotetext{
* Kobe University ** Kyoto University
} 


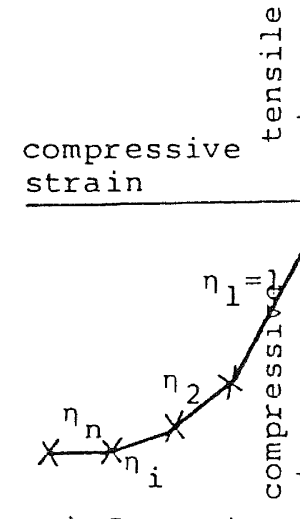

a) Concrete

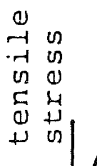

感 tensile
strain

\section{7
0
0
0
0
+1}

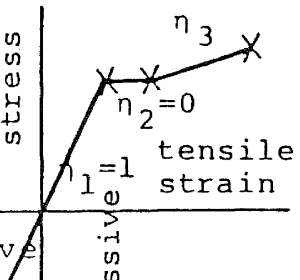

of the equation of motion (Eq. (13)) with respect to time can be obtained by solving Eq. (17). In order to improve the accuracy, the following iterative method was also used:

$$
\begin{gathered}
{[M] \cdot\left(\frac{1}{\beta \cdot \Delta t^{2}} \cdot\{\Delta U\}_{t \rightarrow t+\Delta t}^{i}-\frac{1}{\beta \cdot \Delta t} \cdot\{\dot{U}\} t\right)-\frac{1}{2 \beta}\{\ddot{U}\} t} \\
\quad+[K]_{t+\Delta t} \cdot\{\Delta U\}{\underset{t}{t \rightarrow t+\Delta t}}^{i} \\
=\{\Delta R\}_{t \rightarrow t+\Delta t}-[K]_{t+\Delta t} \cdot\{\Delta U\}_{t \rightarrow t+\Delta t}^{i-1} \\
\quad-\frac{1}{\beta \cdot \Delta t^{2}} \cdot[M] \cdot\{\Delta U\}_{t \rightarrow t+\Delta t}^{i-1}
\end{gathered}
$$

where, $\{\Delta U\}_{t \rightarrow t+\Delta t}^{i}$ is the increase in displacement vector during the iterative time of $i$.

The flow of the iterative process for $\mathrm{Eq}$.

(18) is as follows:

1) Formation of the stiffness matrix $\left[K^{*}\right]$

for Eq. (12) during a time step of $\Delta t$ is shown in the following equation:

$$
\begin{aligned}
{[M] \cdot\{\Delta \ddot{U}\}_{t \rightarrow t+\Delta t}+[K] \cdot\{\Delta U\}_{t \rightarrow t+\Delta t} } \\
=\{\Delta R\}_{t \rightarrow t+\Delta t}
\end{aligned}
$$

As Eq. (13) is simply an approximate equation of motion, it is solved using the Newmark- $\beta$ method which consists of the following equations:

$$
\begin{aligned}
\{U\}_{t+\Delta t}=\{U\}_{t}+\Delta t \cdot\{\dot{U}\}_{t} & +\Delta t^{2} \cdot\left[(1 / 2-\beta)\{\ddot{U}\}_{t}\right. \\
& \left.+\beta\{\ddot{U}\}_{t+\Delta t}\right]
\end{aligned}
$$

The discretized equation for acceleration can be obtained from Eqs. (14) and (15) which describes the evolution of the approximate solution as follows:

$$
\begin{aligned}
\{\Delta \ddot{\mathrm{U}}\}_{t \rightarrow \mathrm{t}+\Delta t} & =\frac{1}{\beta \cdot \Delta \mathrm{t}^{2}} \cdot\{\Delta \mathrm{U}\}_{t \rightarrow t+\Delta t} \\
& -\frac{1}{\beta \cdot \Delta t} \cdot\{\dot{\mathrm{U}}\}_{t}-\frac{1}{2 \beta}\{\ddot{\mathrm{U}}\}_{t}
\end{aligned}
$$

Substituting Eq. (16) into Eq. (13) gives the following equation:

$$
\begin{gathered}
\left([K]+\frac{1}{\beta \cdot \Delta t^{2}}[M]\right) \cdot\{\Delta U\}_{t \rightarrow t+\Delta t}=\{\Delta R\}_{t \rightarrow t+\Delta t} \\
+[M] \cdot\left(\frac{1}{\beta \cdot \Delta t} \cdot\{\dot{U}\}_{t}+\frac{1}{2 \beta}\{\ddot{U}\} t\right)
\end{gathered}
$$

In the above equations, the parameter $\beta$ and the time step $\Delta t$ are closely related to the accuracy of the integration and also the stability of the dynamic solution. In this study, the parameter $\beta=1 / 4$ is used because it satisfies the necessary stability conditions. Based on various calculations, the most appropriate value for the time step $\Delta t$ was selected. The integration

$$
\left[K^{*}\right]=[K]+\frac{1}{\beta \cdot \Delta t^{2}} \cdot[M]
$$

2) Calculation of the constant parts of the load vector

$$
\begin{aligned}
& \left\{\Delta \mathrm{R}^{*}\right\}_{t \rightarrow t+\Delta t}=\{\Delta \mathrm{R}\}_{t \rightarrow t+\Delta t} \\
& +[M]\left(\frac{1}{\beta \cdot \Delta t}\{\dot{U}\}_{t}+\frac{1}{2 \beta}\{\ddot{U}\}_{t}\right)
\end{aligned}
$$

3) Setting of the initial values for the variable parts of the load vector

$$
\left\{R_{E r r}\right\}^{i=0}=0
$$

4) Formation of the load vector

$$
\left\{\Delta R^{*}\right\}_{t \rightarrow t+\Delta t}^{i}=\left\{\Delta R^{*}\right\}_{t \rightarrow t+\Delta t^{+}}\left\{R_{E r r}\right\}^{i-1}
$$

5) Calculation of the discrete increment in displacement $\{\Delta U\} \hat{t}_{t \rightarrow t}^{i} \Delta t$ using the band matrix method.

6) Calculation of the variable parts of the load vector

$$
\begin{aligned}
\left\{\Delta \mathrm{R}_{\operatorname{Err}}\right\}^{i}=-[\mathrm{K}]_{t+\Delta t} \cdot\{\Delta \mathrm{U}\}_{\mathrm{t}+\Delta t}^{i} \\
-\frac{1}{B \cdot \Delta \mathrm{t}^{2}}[\mathrm{M}]\{\Delta \mathrm{U}\}_{\mathrm{t} \rightarrow \mathrm{t}+\Delta t}^{i} \\
\left\{\mathrm{R}_{\operatorname{Err}}\right\}^{i}=\left\{\mathrm{R}_{\operatorname{Err}}\right\}^{i-1}+\left\{\Delta \mathrm{R}_{\operatorname{Err}}\right\}^{i}
\end{aligned}
$$

7) Decision on degree of convergence

$$
\left\|\left\{\Delta \mathrm{R}_{\operatorname{Err}}\right\}^{i}\right\| /\left\|\left\{\mathrm{R}_{\operatorname{Err}}\right\}^{i}\right\| \leq \text { tol. }
$$

where the abbreviation 'tol.' stands for the amount of tolerance while \|\| is the Euclidean Norm.

If the above equation is satisfied, the succeeding step would be step 8). Otherwise the flow will return to step 4 ). 
impact resistance. Based on the knowledge obtained about these factors, some design concepts will be proposed.

\section{ANALYTICAL INVESTIGATION}

\section{Finite Element Model for RC Beams}

Doubly reinforced $\mathrm{RC}$ beams were modelled using rectangular elements for concrete and line elements for reinforcement as shown in Figs. 1 a) and 1 b).

The dimensions of the RC beams were as follows: total depth $=16 \mathrm{~cm}$; $w i d t h=15 \mathrm{~cm}$; total length $=130 \mathrm{~cm} ; \operatorname{span}=120 \mathrm{~cm}$. The beams were of simple support with a locally distributed load acting at midspan (length of distributed load $=16 \mathrm{~cm}$ ). Two deformed bars (DIOmm) were used as compression reinforcement while three similar bars were used in tension. The beams were designed according to the allowable stress design method with a designed load $\left(\mathrm{P}_{\mathrm{d}}\right)$ of $18.6 \mathrm{kN}$ (1.9tf). $\$ 6 \mathrm{~mm}$ reinforcement was used as vertical stirrups as shown in Fig. $1 \mathrm{~b}$ ).

\section{Non-Linear Model}

The constitutive model for behaviour in the elasto-plastic region was based on the method proposed by Isobata [4]. Since it is natural for cracks to appear in concrete, it shall be considered as an orthotropic body. The elasto-plastic body is assumed to have a modulus of elasticity of $\mathrm{E}_{\mathrm{p}}$ and Poisson's ratio of $v_{p}$ as opposed to $(E, v)$ for an isotroplc elastic body. Using conversion parameters $(n, \xi)$ obtained from the uniaxial material characteristic, the elasto-plastic body can be expressed in terms of $E, \nu, \eta, \xi$. The axes $x, y$ are taken along the direction of main stresses. The conversion parameters can thus be defined as follows:

$$
\begin{aligned}
& E_{x}=n_{x} \cdot E, E_{y}=n_{y} \cdot E, G_{x y}=n_{x y} \cdot G \\
& \nu_{x}=\xi_{x} \cdot \nu, \nu_{y}=\xi_{y} \cdot \nu, \nu_{x} \cdot \nu_{y}=\xi_{x y}^{2} \cdot v^{2}
\end{aligned}
$$

The following equation can be assumed from the Maxweli-Betti's Reciprocal Theorem:

$$
\nu_{y} \cdot E_{x}=\nu_{x} \cdot E_{y}=\xi_{x y} \cdot\left(n_{x} \cdot n_{y}\right)^{1 / 2} \cdot v \cdot E
$$

The modulus of rigidity $G_{x y}$ can be expressed as a function of the modulus of elasticity and Poisson's ratio of the various axes:

$$
\begin{aligned}
& G_{x y}=\frac{E_{x}^{1 / 2} \cdot E_{y}^{1 / 2}}{2\left(1+v_{x}^{1 / 2} \cdot v_{y}^{1 / 2}\right)}=\frac{n_{x}^{1 / 2} \cdot n_{y}^{1 / 2} \cdot E}{2\left(1+\xi_{x y} \cdot v\right)} \\
& \xi_{x y}=\xi_{x}^{1 / 2} \cdot \xi_{y}^{1 / 2}
\end{aligned}
$$

From Eqs. ( 1 ) and (3), the following relation is obtained:

$$
n_{x y}=\frac{1+v}{I+\xi_{x y} \cdot v} \cdot n_{x}^{1 / 2} \cdot n_{y}^{1 / 2}
$$

The stress-strain relationship at the plane stress field of the orthotropic elastoplastic body is thus:

$$
\begin{aligned}
& \left\{\sigma_{X}, \sigma_{y}, \tau\right\}^{\tau}=\left[D_{e p}\right] \cdot\left\{\varepsilon_{x}, \varepsilon_{y}, \gamma\right\}^{\tau} \\
& {\left[D_{e p}\right]=\left[A_{p}\right]^{\tau} \cdot\left\{[D]+\left[H_{p}\right]\right\} \cdot\left[A_{p}\right]} \\
& {[D]=\frac{E}{1-v^{2}}\left[\begin{array}{ccc}
1 & v & 0 \\
\nu & 1 & 0 \\
0 & 0 & (1-v) / 2
\end{array}\right]} \\
& {\left[\mathrm{A}_{\mathrm{p}}\right]=\left[\begin{array}{ccc}
n_{\mathrm{x}}^{1 / 2} & 0 & 0 \\
0 & n_{\mathrm{y}}^{1 / 2} & 0 \\
0 & 0 & n_{\mathrm{x}}^{1 / 4} \cdot \eta_{\mathrm{y}}^{1 / 4}
\end{array}\right]} \\
& {\left[H_{p}\right]=\frac{\left(\nu_{p}-\nu\right) \cdot E}{\left(1-\nu_{p}^{2}\right)\left(1-v^{2}\right)} \text {. }} \\
& {\left[\begin{array}{ccc}
\nu+\nu_{p} & 1+\nu \cdot \nu_{p} & 0 \\
1+\nu \cdot \nu_{p} & \nu+\nu_{p} & 0 \\
0 & 0 & -(I-\nu) \cdot\left(1-\nu_{p}\right) / 2
\end{array}\right]} \\
& \nu_{p}=\left(\xi_{x} \cdot v \cdot \xi_{y} \cdot x\right)^{1 / 2}=\xi_{x y} \cdot v
\end{aligned}
$$

The conversion parameter $n$ for modulus of elasticity in the elasto-plastic body as used in Eq. (9) is obtained from the idealized stress-strain curve for concrete as illustrated in Fig. 2 a). As for Poisson's ratio, it is to be assumed to be $\xi=1.0$. The stress-strain relationship of concrete below the tensile stress limit is considered to be linear as in Fig. 2 a). During tensile rupture, the elastic strain energy released is converted into equivalent nodal forces acting on the surrounding nodes. Shear transmission at the crack surface has been disregarded in this study. The bond between concrete and reinforcement is supposed to have an effect on the analysis, but in this study it is assumed that the bond remains perfect. The same method is also used to define the elasto-plastic model for the reinforcement.

\section{Dynamic Solution of Equilibrium}

Since the time in which loading is comparatively short during impacts, the effect of viscous damping in the beams becomes small enough to be ignored. The semidiscrete equation of motion for the finite element assembly can be written as follows:

$$
[M] \cdot\{\ddot{U}\}_{t}+[K] \cdot\{U\}_{t}=\{R\}_{t}
$$

where, $[M],[K]$ represents the mass and stiffness matrices respectively while $\{R\}$ is the external forces vector. $\{\ddot{U}\} t^{\prime}\{U\}$ are the acceleration and displacement vectors for the finite element assembly respectively. The discretized equation 
8) Calculation of the displacement, acceleration and velocity

$$
\begin{gathered}
\{u\}_{t+\Delta t}=\{\}_{t}+\{\Delta U\}_{t \rightarrow t+\Delta t}^{i} \\
\{\ddot{U}\}_{t+\Delta t}=\frac{1}{\beta \cdot \Delta t^{2}}\{\Delta\}_{t \rightarrow t+\Delta t}^{i} \frac{1}{\beta \cdot \Delta t}\{\dot{U}\} t \\
\quad-\frac{1}{2 \beta}\{\ddot{U}\}_{t}+\{\ddot{U}\} t \\
\{\dot{U}\}_{t+\Delta t}=\{\dot{U}\}_{t}+\frac{1}{2} \Delta t(\{\ddot{U}\} t+\{\ddot{U}\} t+\Delta t
\end{gathered}
$$

\section{EXPERIMENTAL INVESTIGATION}

\section{Testing Program and Test Procedures}

In order to verify the validity of calculations using the above-mentioned model, $\mathrm{RC}$ beams similar to those used in the analysis were made and then subjected to both static and impulsive tests. SD30 $\left(\sigma_{\text {sy }}=3.62 \mathrm{MPa} ; 36.9 \mathrm{kgf} / \mathrm{mm}^{2}, \sigma_{\mathrm{su}}=4.68 \mathrm{MPa} ;\right.$ $47.8 \mathrm{kgf} / \mathrm{mm}^{2}$ ) reinforcement was used in the beams which had a designed strength of $\sigma_{\mathrm{ck}}=29.4 \mathrm{MPa} ; 300 \mathrm{kgf} / \mathrm{cm}^{2}$ for concrete.

The static and impact tests were carried out in different test frames. For the former, a $1960 \mathrm{kN}$ (200tf) universal testing machine was used. RC beams of simple support were loaded through a square steel plate $(15 \mathrm{~cm} \times 15 \mathrm{~cm} \times 1 \mathrm{~cm})$ placed at midspan. Loads of up to $9.8 \mathrm{kN}$ ( $1 \mathrm{tf}$ ) for the elastic test as well as failure test under continuous loading were carried out. On the other hand, impulsive tests were carried out using the apparatus shown in Fig. 3. Flat cages were placed on the friction plane while load cell with ball bearings were fixed to the bottom of the beam ends to make it freely rotatory and thus give the effect of simple support. Moreover, the ends were bolted to prevent it from lifting off its supports. A mass of $100 \mathrm{~kg}$ was dropped from various heights at midspan to induce impulsive force. A rubber pad was placed on the loading plate to provide soft impacts. The beam, rubber pad and mass were considered to behave as one single body during the force action. Besides that, it is assumed here that the rubber pad causes no damping. In the experiments carried out, $\mathrm{h}=1 \mathrm{~cm}$ was used for the elastic test while $\mathrm{h}=60 \mathrm{~cm}$ was used for the failure test. Measurements for strain deflection, acceleration, crack conditions and failure conditions were taken at points indicated on Fig. 3 .

\section{Verification of Analytical Results}

In the analysis for impulsive loading, impact force-time relations obtained from the falling mass in the experiment was used as input values for the acting force. Figs. 4 a) and 4 b) show the impact force-time relations of the elastic test and also for tests till failure respectively. From the figures, it is clear that the loading rate changes with time during impulsive loading.

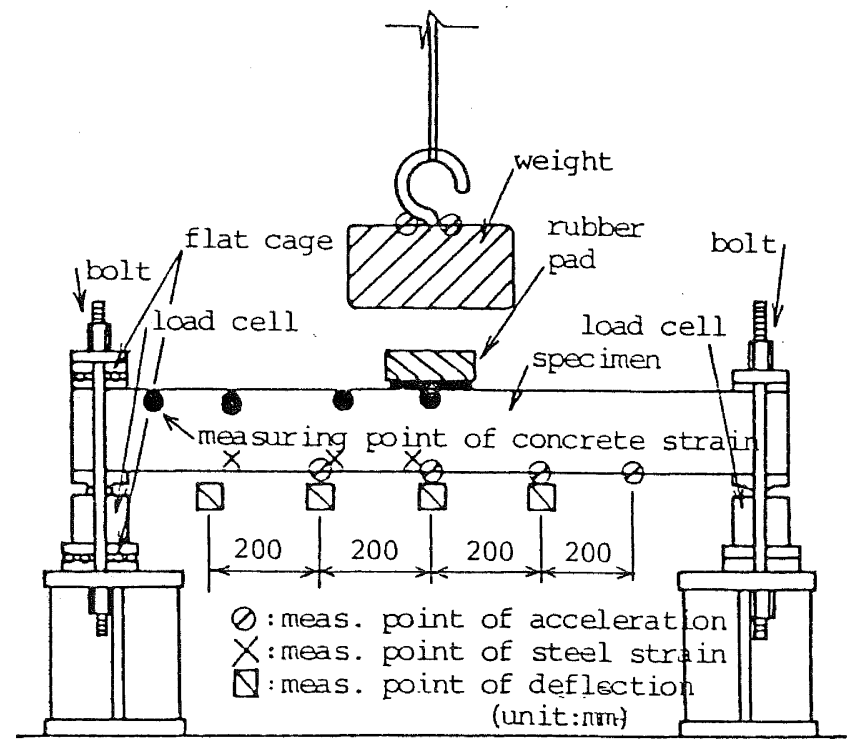

FIGURE 3 : TEST APPARATUS AND MEASURING POINT OF DEFLECTION, ACCELERATION AND STRAIN

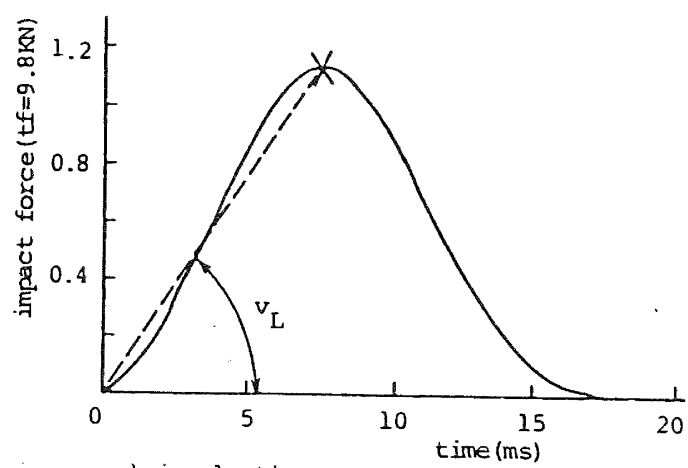

a) in elastic

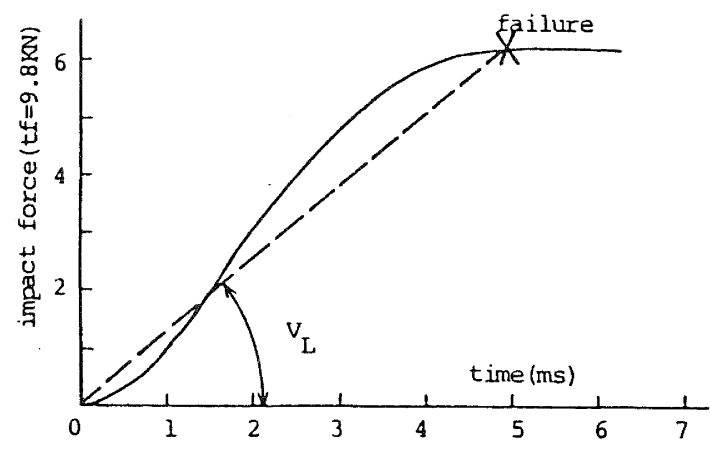

b) at failure

FIGURE 4 : IMPACT FORCE-TIME FUNCTIONS AND DEFINITION OF LOADING RATE 

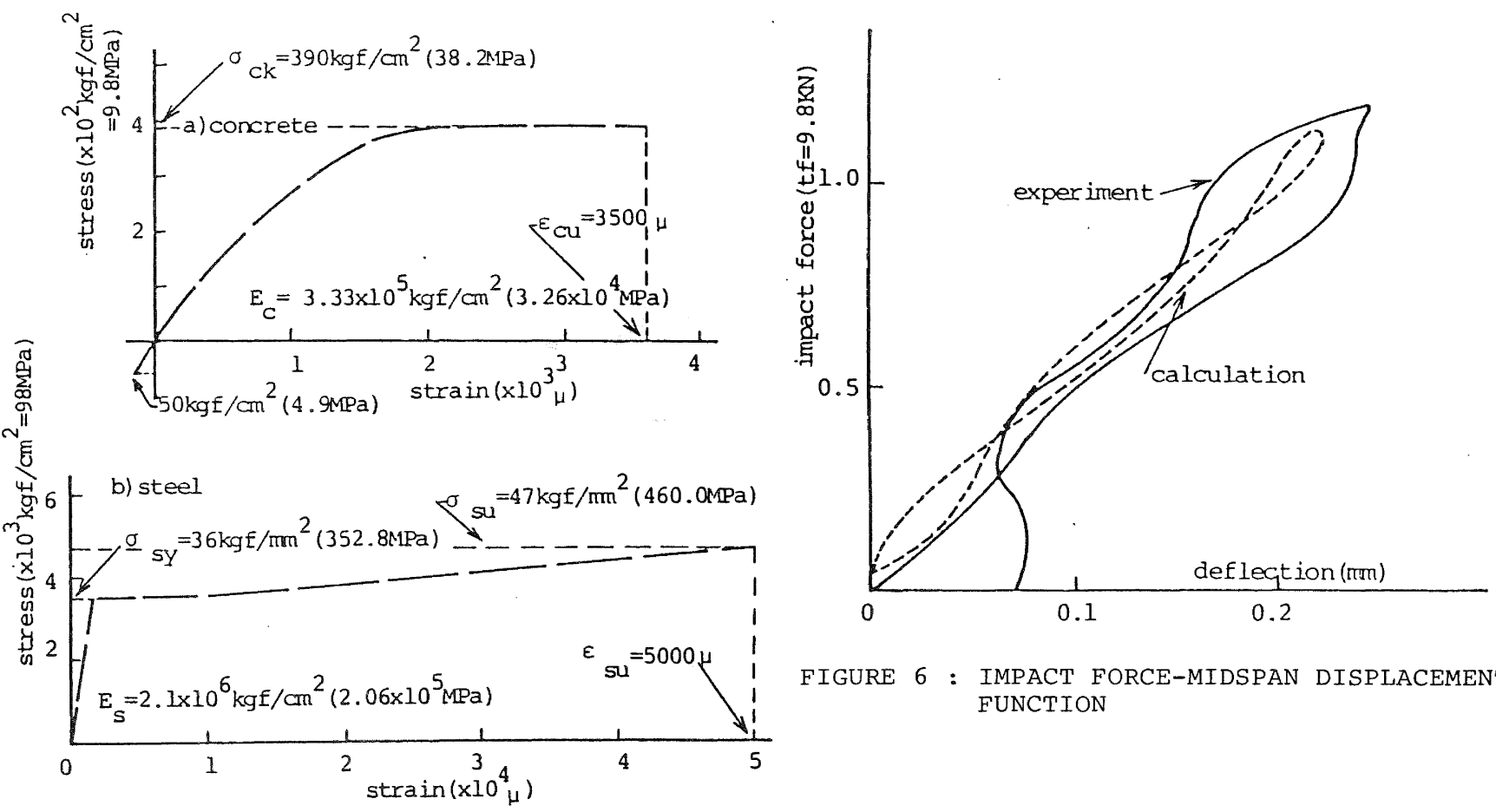

FIGURE 6 : IMPACT FORCE-MIDSPAN DISPLACEMENT

FIGURE 5 : IDEALIZED STRESS-STRAIN DIAGRAMS FOR STEEL AND CONCRETE

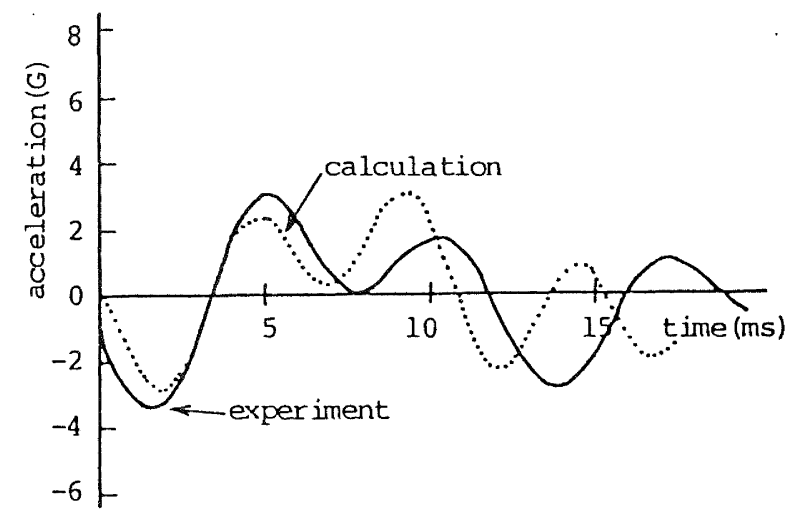

FIGURE 7 : MIDSPAN ACCELERATION-TIME FUNCTION

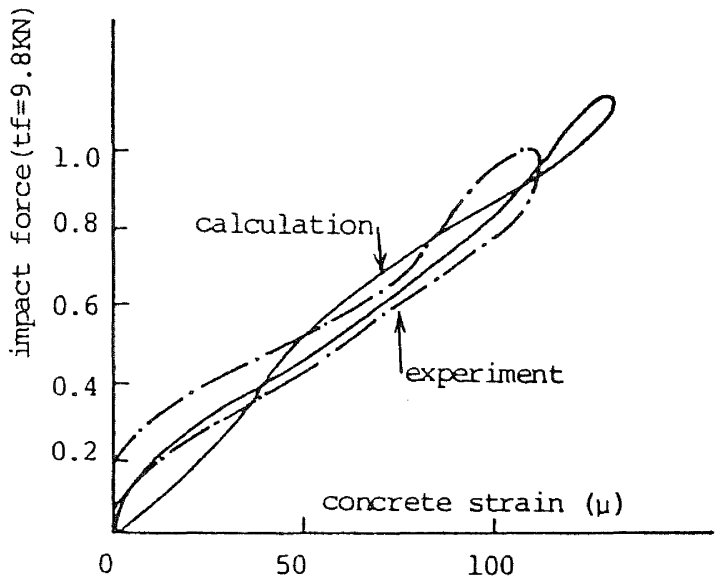

FIGURE 9 : LOAD (IMPACT FORCE)-MIDSPAN DISPLACEMENT FUNCTIONS

FIGURE 8 : IMPACT FORCE-CONCRETE STRAIN FUNCTION 
A simplified way of determining the loading rate was used in this study. For calculations within the elastic region, the average loading rate between the initial time of loading and the time at which maximum loading occurs was considered. In the calculations until failure, the average loading rate between the initial loading and failure was used (Refer Fig. 4). In this analysis, the material characteristic for the various materials was based on results of static uniaxial tests as shown in Figs. 5 a) and $5 \mathrm{~b}$ ). It is thought that the stress-strain curve of the materials are affected by the strain rate, stress conditions etc. but since it has yet to be quantitatively made clear, static uniaxial test results will be used in this analysis. (The effects of strain rate, stress conditions etc. on the stress-strain curve of various materials will be carried out in future studies.) Under this assumption, the effects of inertia on material characteristics were carried out and the results were subsequently compared with results from tests for verification.

Figs. 6-8 show the comparison between calculations and test results of beams under impulsive loading in the elastic region. From the hysteresis curve for deflection in Fig. 6, it can be concluded that there is no distinct difference in stiffness for both cases even though the curve shapes are quite different. This is assumed to be caused by support conditions for the beam or effects of noise during measurement of discrete deflections. Fig. 7 shows a comparison of the acceleration response which relates to the amount of displacement. From the shape of the curves, it is clear that a component of vibration with constant frequency also exists. The frequency for both cases were quite similar with test results being $167 \mathrm{~Hz}$ while calculations came up to approximately $180 \mathrm{~Hz}$. Fig. 8 shows the strain hysteresis of concrete at midspan and it can be said that the accuracy is of a satisfactory level.

Calculation and test results of beams under static as well as impulsive loading within the elasto-plastic region is shown in Figs. 9-12. Figs. 9 a) and 9 b) show the loadmidspan displacement curves for static and impulsive loads respectively. Under static loading, the initial stiffness were roughly similar but as cracks begin to appear, they too begin to differ with calculations being 0.7 times that of tests while it decreased to about 0.88 times at failure. For impulsive loads, the initial stiffness was quite similar too but at failure the calculations only came to a value of 0.92 times that of test results. Next, we shall carry out verification by means of the total energy. Total energy here is defined by the area below the load-displacement curve when failure occurs under a single impulsive load.

Total energy derived from Fig. 9 is shown in Table 1. Under static load, the total energy for centre deflection of up to $1.0 \mathrm{~mm}$ is 1.12 times that of the experimental value. For centre deflections of less than $3.0 \mathrm{~mm}$, calculation values were roughly

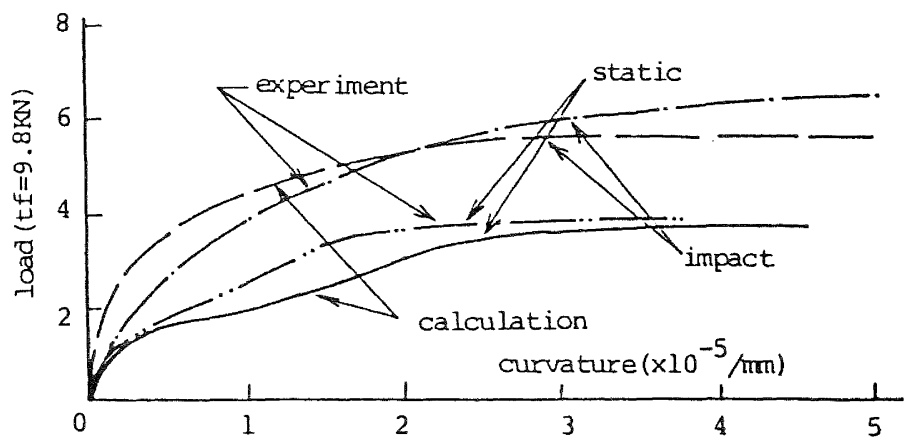

FIGURE 10 : LOAD (IMPACT FORCE)-CURVATURE FUNCTIONS

smaller, that is about 0.95 times that of the experiment results. Fig. 10 gives a comparison of load(impact)-curvature relat-tions of static and impulsive loadings. Under both types of loads, the curve shapes were quite similar but the curves from experiments had a slower increase in curvature. Curvature in this case is defined by the average curvature calculated from deflection at positions shown in Fig. 3 . Figs. $11 \mathrm{a}$ ) and $11 \mathrm{~b})$ show the conditions of cracks at failure under both types of loads. There is a similarity in the direction in which cracks form in both cases but the extent is siightly smaller in the calculations. The calculations show that there is a tendency for the area in which cracks form to be smaller in the case of impulsive loads and this result can be verified from the experiments too. Fig. 12 shows the comparison of impact forcesteel strain at various points under impact. On the whole, the calculations can be said to match the experiments but there is a tendency for the expansion of steel strain to occur faster in analysis.

TABLE 1 : TOTAL ENERGY

\begin{tabular}{ll}
\hline $\begin{array}{l}\text { Total } \\
\text { energy } \\
\text { up to 1.0mm }\end{array}$ & $\begin{array}{l}\text { Total } \\
\text { upergy } 3.0 \mathrm{~mm}\end{array}$ \\
$\begin{array}{l}\text { centre } \\
\text { deflection } \\
\text { centre } \\
\text { deflection } \\
(\mathrm{J})\end{array}$ & $\begin{array}{l}\text { tf } \mathrm{m} \\
\mathrm{10} 0^{-3} \mathrm{tf} \mathrm{m} \\
(\mathrm{J})\end{array}$ \\
\hline $1.36(13.3)$ & $7.9(77.4)$ \\
\hline $1.52(14.9)$ & $7.10(69.58)$ \\
\hline $3.30(32.3)$ & $14.5(142.1)$ \\
\hline $3.31(32.4)$ & $13.8(135.2)$ \\
\hline
\end{tabular}

\section{Effects of Loading Rates on RC Beam Behaviour}

Comparison between static calculations and impulsive calculations (various loading rates) is necessary in the characterization of impulsive behaviour of RC beams. Based on the impact force-time relation shown in 
C.L.

C.L.

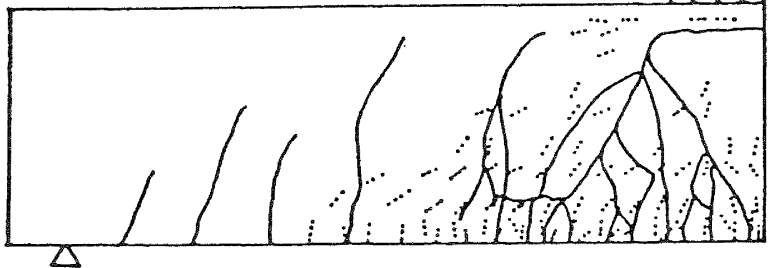

a) Static

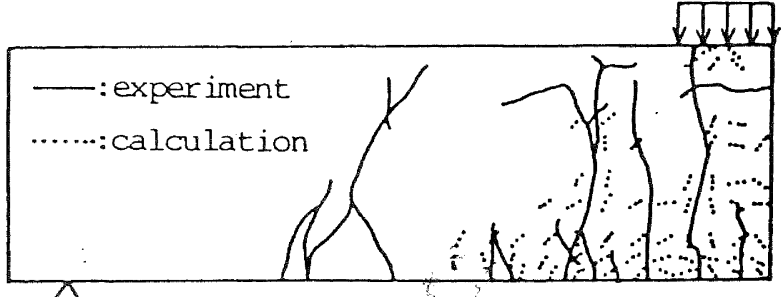

b) Impact

FIGURE 11 : CRACK PATTERNS AT FAILURE

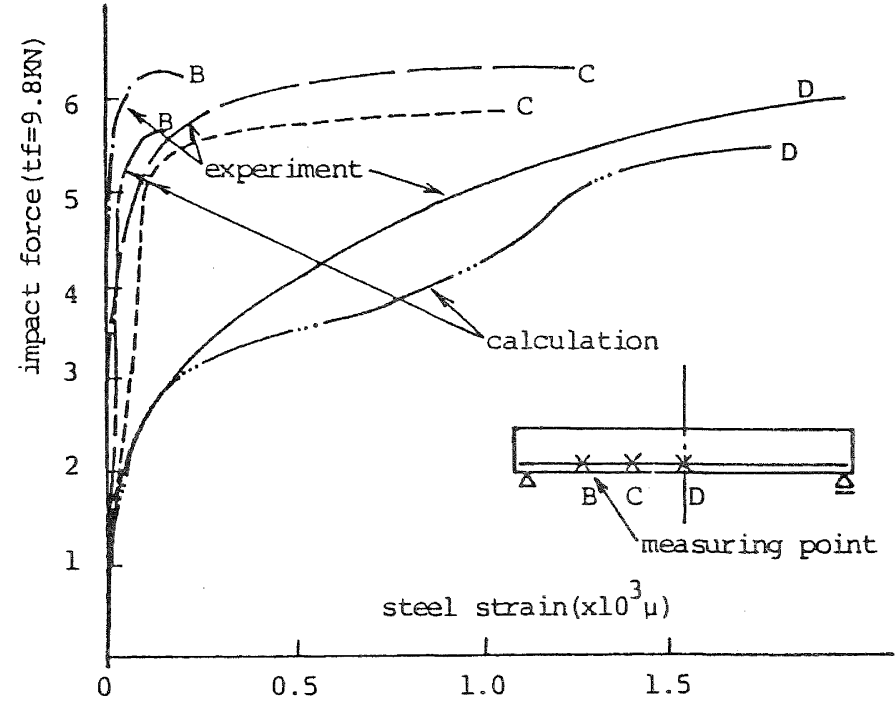

FIGURE 12 : IMPACT FORCE-STEEL STRAIN FUNCTIONS

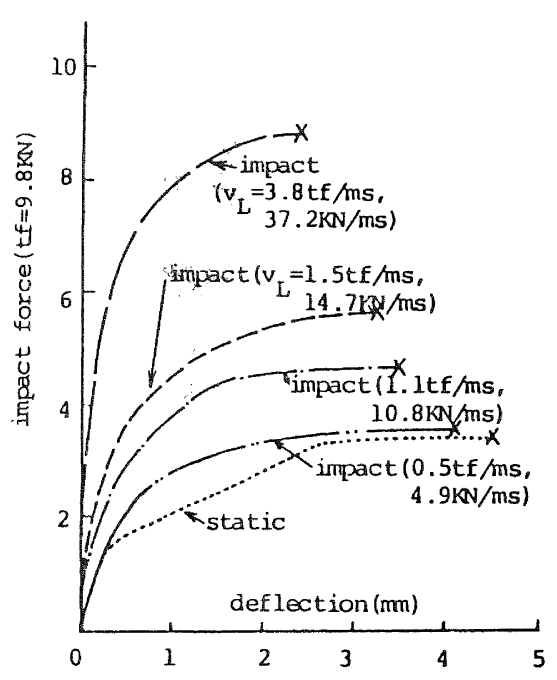

FIGURE 14 : IMPACT FORCE-MIDSPAN DISPLACEMENT FUNCTIONS FOR VARIOUS LOADING RATES

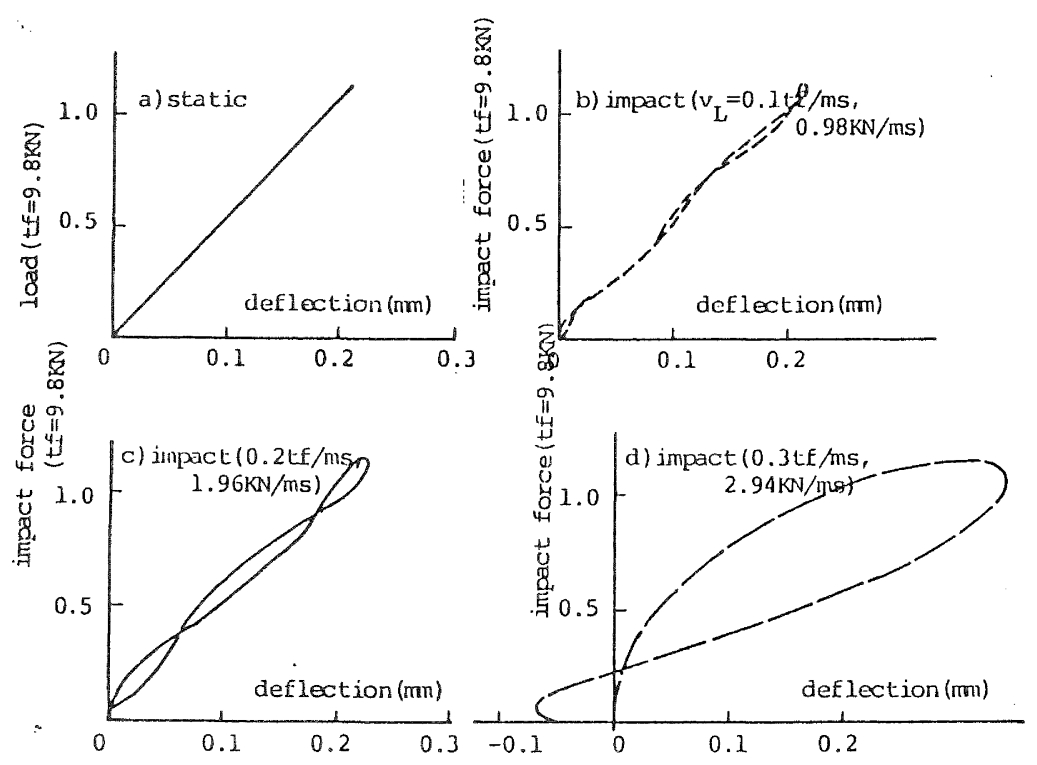

FIGURE 13 : IMPACT FORCE-MISPAN DISPLACEMENT FUNCTIONS FOR VARIOUS LOADING RATES 


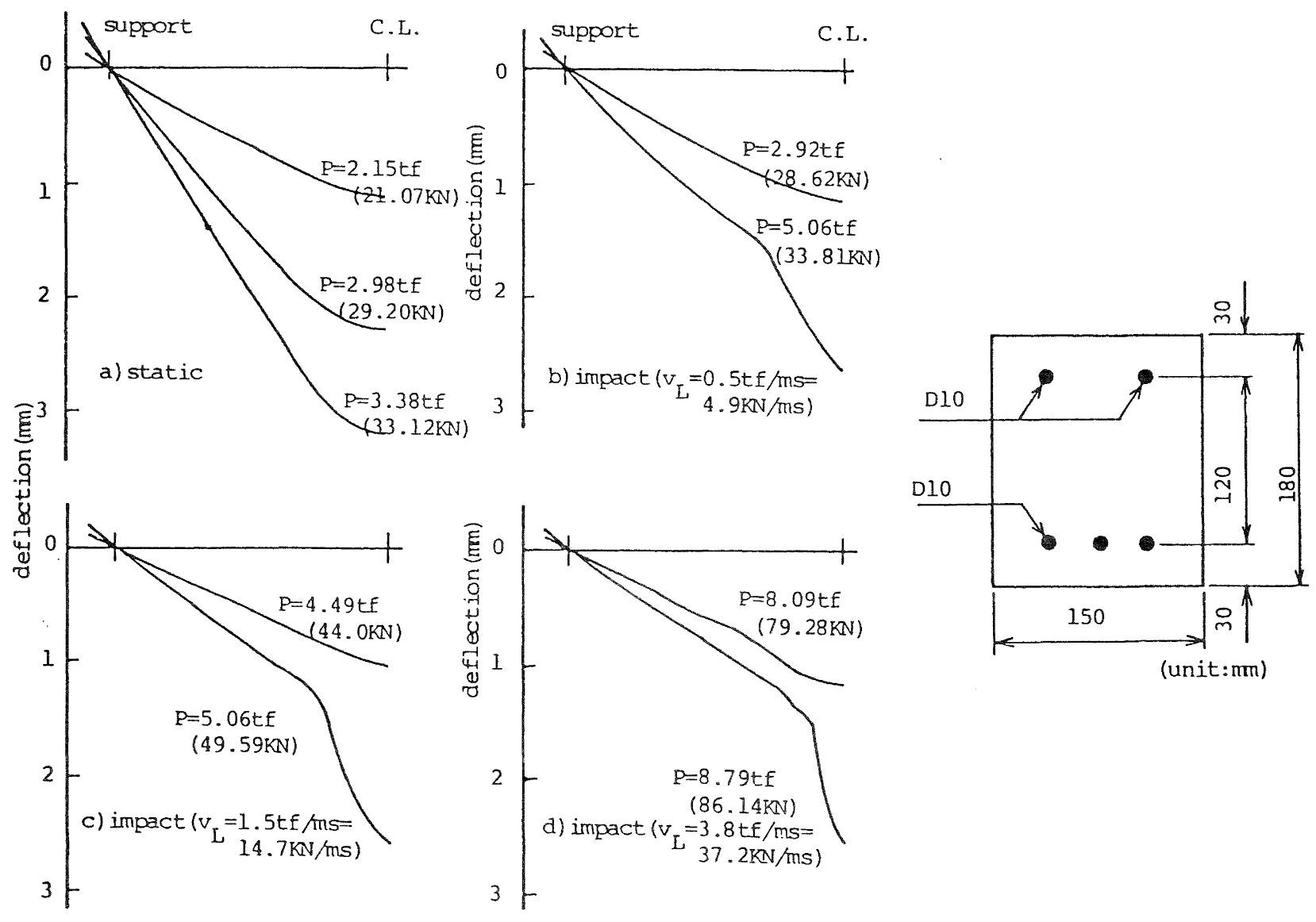

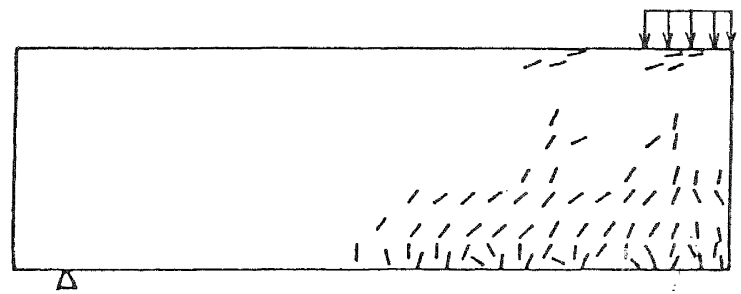

a) static

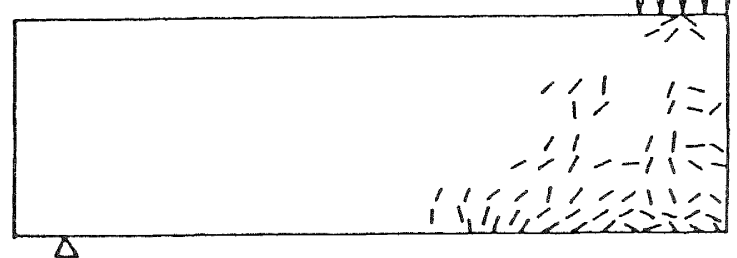

c) $\operatorname{impact}\left(v_{L}=1.5 \mathrm{tf} / \mathrm{ms}=14.7 \mathrm{~kJ} / \mathrm{ms}\right)$

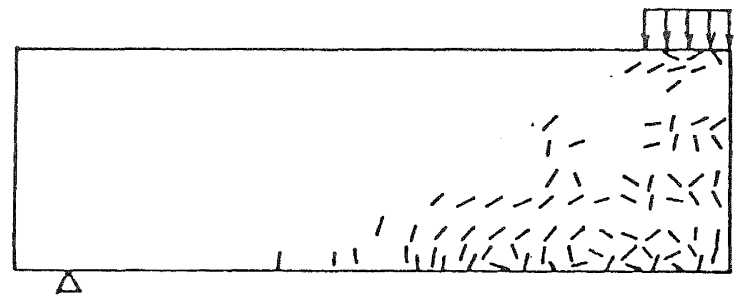

b) $\operatorname{impact}\left(\mathrm{v}_{\mathrm{L}}=0.5 \mathrm{tf} / \mathrm{ms}=4.9 \mathrm{KN} / \mathrm{ms}\right)$

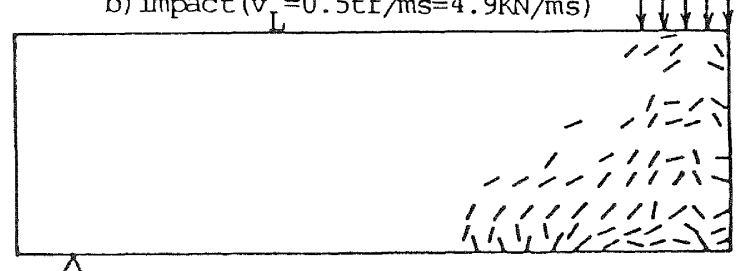

d) $\operatorname{inpact}\left(\mathrm{v}_{\mathrm{L}}=3.8 \mathrm{tf} / \mathrm{ms}=37.2 \mathrm{KN} / \mathrm{ms}\right)$ 
Figs. 4 a) and 4 b) different loading rates were obtained by altering the maximum impact force and duration of loading.

Firstly, the elastic behaviour will be examined. Figs. 13 a)-d) are the impact force-midpsan displacement for static and impulsive loads. From the figures, it can be seen that unlike under static loading, the hysteresis curve for impacts tend to be in a loop form. This can be attributed to inertia which varies with the loading rates. Under a slow loading rate, the stiffness for maximum displacement is quite similar to that of static loading except for some effects of vibration in the curve. On the other hand, as the loading rate increases, the number of waves in the hysteresis curve decreases but an increse in wave amplitude can be noticed. In the case of $v_{L}=2.9 \mathrm{kN} / \mathrm{ms}(0.3 \mathrm{tf} / \mathrm{ms})$, the initial stiffness increased tremendously with the occurrence of large deflection caused by vibrational effects. Besides that, there is a tendency for maximum deflection being much slower than the maximum load. As for the shape of the curves, increase in wave amplitude due to inertia causes the curve to have a negative deflection. Faster loading rates causes an increased inertial effect and also a change in the shape of the hysteresis curve. This result is in accordance with the experiments.

Next, we shall consider the elasto-plastic behaviour. Fig. 14 shows the load-displacement curves of static and impulsive loads. It is clear that an increase in loading rate increases the effects of inertia followed by increases in stiffness and failure load too. It can also be confirmed that deflection tends to be similar in this case. The main difference between the curves for static and impulsive loads lies in stiffness after cracks. In other words, for impacts, there is a smooth transition from elasticity to plasticity without sudden drops in stiffness but in the case of static loading, a sudden drop in stiffness occurs after cracks and then becomes steady again and finally inflects as it nears the failure stage.

Figs. 15 a)-d) show the distribution of deflection both under static and impulsive loads. By comparing the distribution at failure, it can be seen that for static loads, the curve is quite smooth. Under impulsive loading, local deformation at midspan becomes large at failure and the curve differs from those under static loading. This becomes clearer as the loading rate increases. It can be concluded that local deformation is more likely to occur under impulsive loading. Moreover, the deformation capabilities tend to decrease too, thus forcing the structures to be under very severe conditions. Figs. 16 a) -d) show the conditions of cracks at failure. The region where cracks occur are smaller during impacts, especially when the loading rate is high. In other words, under a high loading rate, energy absorption at failure occurs only in a limited region which causes large cracks to form around this area.

\section{DESIGN CONCEPTS FOR IMPULSIVE LOADING}

\section{Design Related Properties}

The characteristic behaviour of RC beams during impact has been discussed in the previous section. From experiments carried out on concrete members, it is known that a drop in concrete toughness usually occurs during impacts.

From these results, an evaluation method on concrete members under impulsive loading can be carried out based on the following items:

1) Degree of improvement in load capacity.

2) Degree of suppression of drop in deformation capability at failure.

3) Degree of suppression of drop in toughness.

4) Degree of suppression of critical local deformation.

5) Degree of suppression of increase in failure affected region.

The above-mentioned items will be quantitatively evaluated and followed by recommendation of improvements necessary for impact resistance. The evaluation of those items will be based on the following indexes.

(i) Characteristics of the hysteresis curve and failure energy

(ii) Curvature at failure

(iii) Failure region

Index (i) will be used to evaluate items 1) -3) while index (ii) will be used for item 4) and index (iii) for item 5). A few factors considered to have effects on the impact behaviour of RC beams will be introduced here. They are beam depth, concrete strength, usage of high yield strength steel and addition of steel fibre. Beam depth was set at $h=18 \mathrm{~cm}$ using the configurations in Figs. 1 and 17. This beam shall be referred to as the $h-18$ beam here onwards. As comparison to the normal strength concrete ( $\sigma_{\mathrm{ck}}=38.2 \mathrm{MPa} ; 390 \mathrm{kgf} /$ $\left.\mathrm{cm}^{2}\right)$, high strength concrete $\left(\sigma_{\mathrm{ck}}=84\right.$.3MPa; $860 \mathrm{kgf} / \mathrm{cm}^{2}$ ) was also used and it will be called the $\sigma-860$ beam (Refer Fig. 18).

High yield strength steel with characteristics such as shown in Fig. 19 was also used and it will be referred to as the HT beam. In the case of steel fibre reinforced concrete, a model derived from Hannant's Theory [2] was employed. An improved ultimate tensile strain was applied to the uniaxial tensile curve (See Figs. 20 a) and 20 b)). Two different amounts of fibre reinforcement in terms of volume were used; $\mathrm{V}_{f}=1.33 \%$ and $3.0 \%$. The former will be called the SF-133 beam and the latter the $\mathrm{SF}-3$ beam.

\section{Impact Resistance Behaviour of RC Beams}

\section{(a) Improvement in load resistance}

The failure load-loading rate relation for the various types of beams is shown in Fig. 21. Under impulsive loading the load capacity shows an increase because of inertia. The effects of inertia depends on the sensitivity of the failure load-loading 


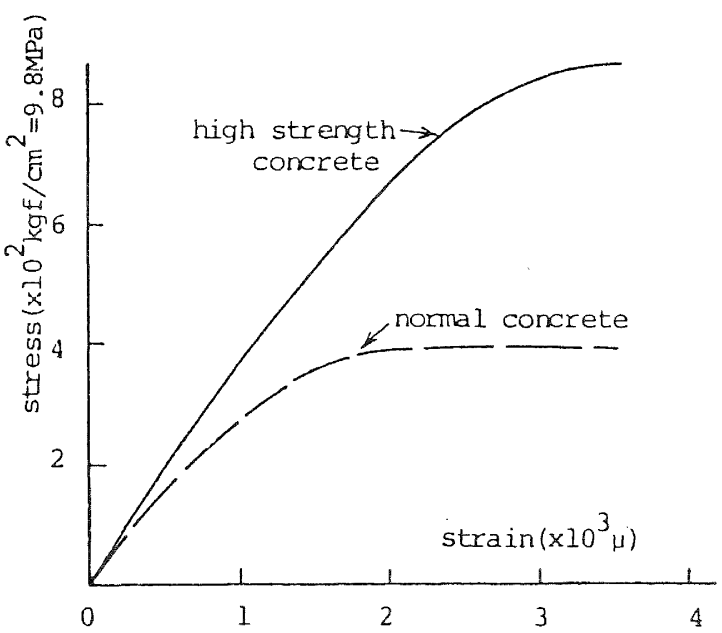

FIGURE 18 : IDEALIZED STRESS-STRAIN DIAGRAM FOR HIGH STRENGTH CONCRETE

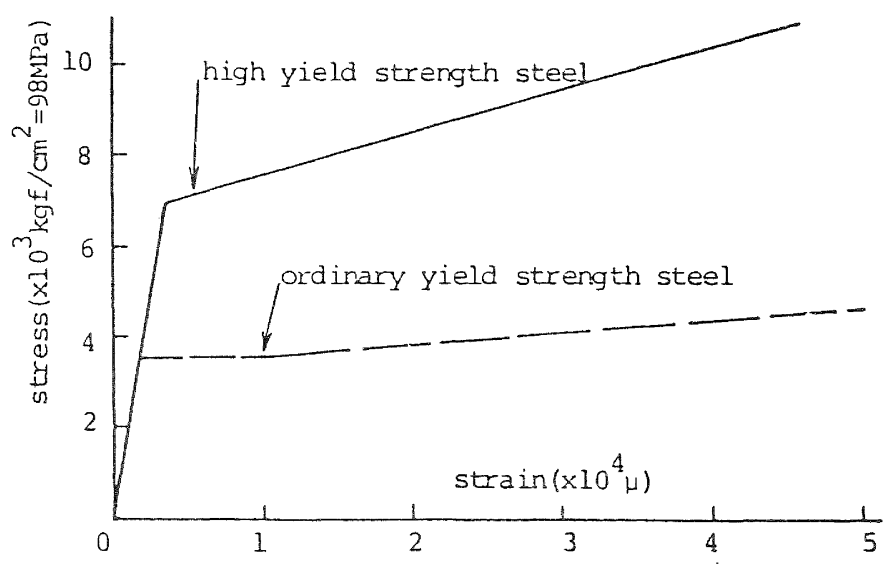

FIGURE 19 : IDEALIZED STRESS-STRAIN DIAGRAM FOR HIGH YIELD STRENGTH STEEL

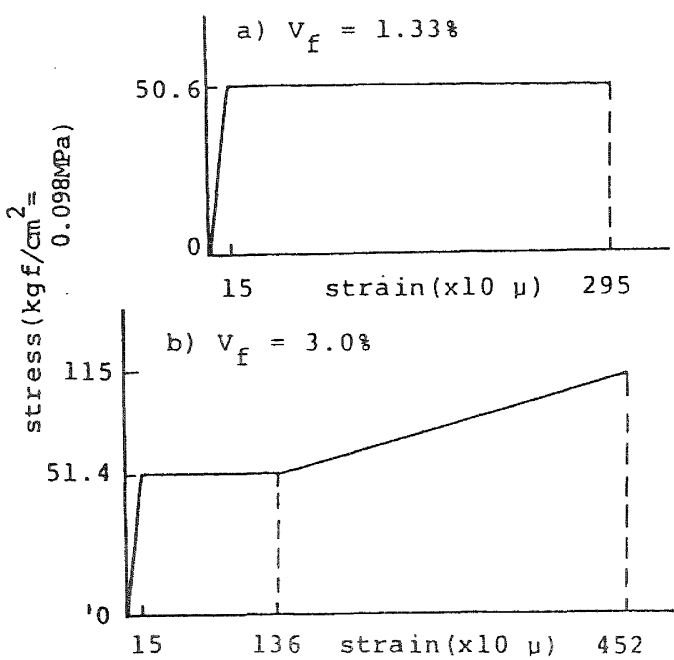

FIGURE 20: IDEALIZED STRESS-STRAIN DIAGRAMS OF STEEL FIBRE REINFORCED CONCRETE

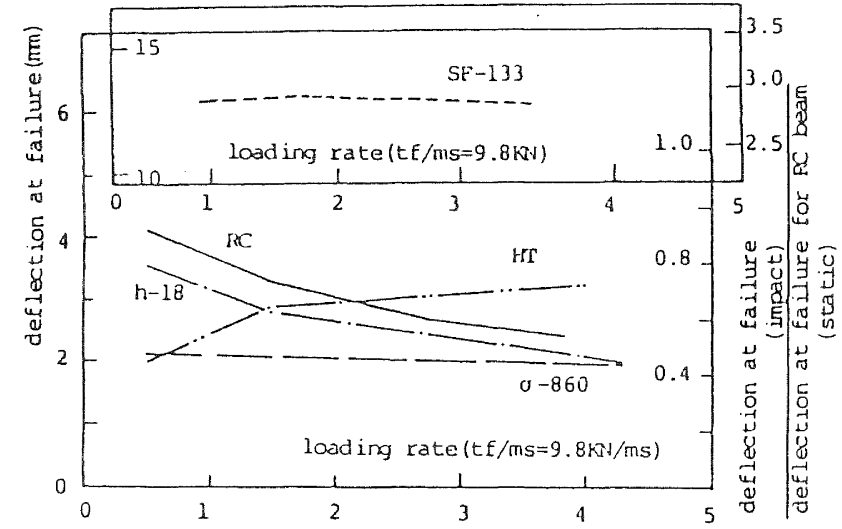

FIGURE 22 : EFFECT OF LOADING RATE () DEFLECTION AT FAILURE

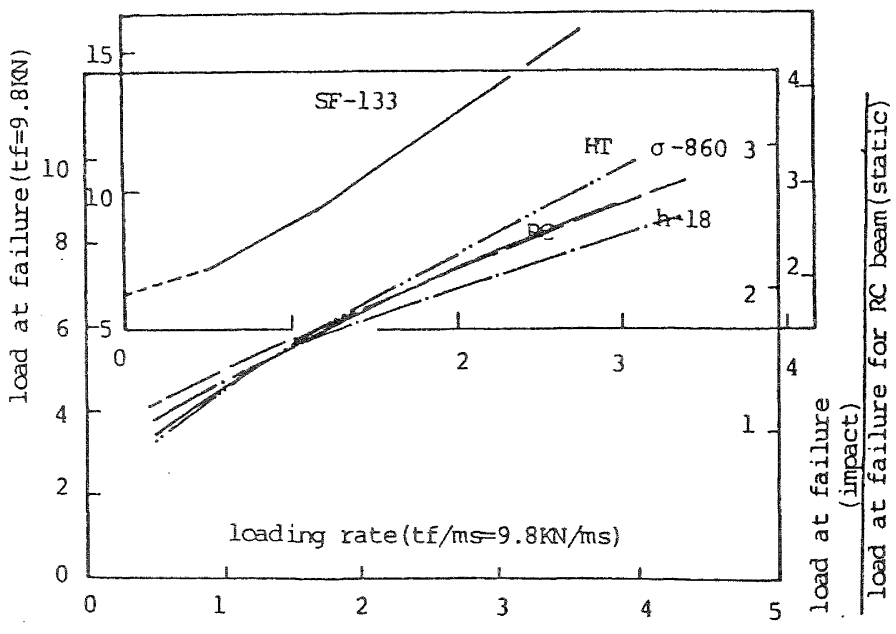

FIGURE 21 : EFFECT OF LOADING RATE ON LOAD AT FAILURE

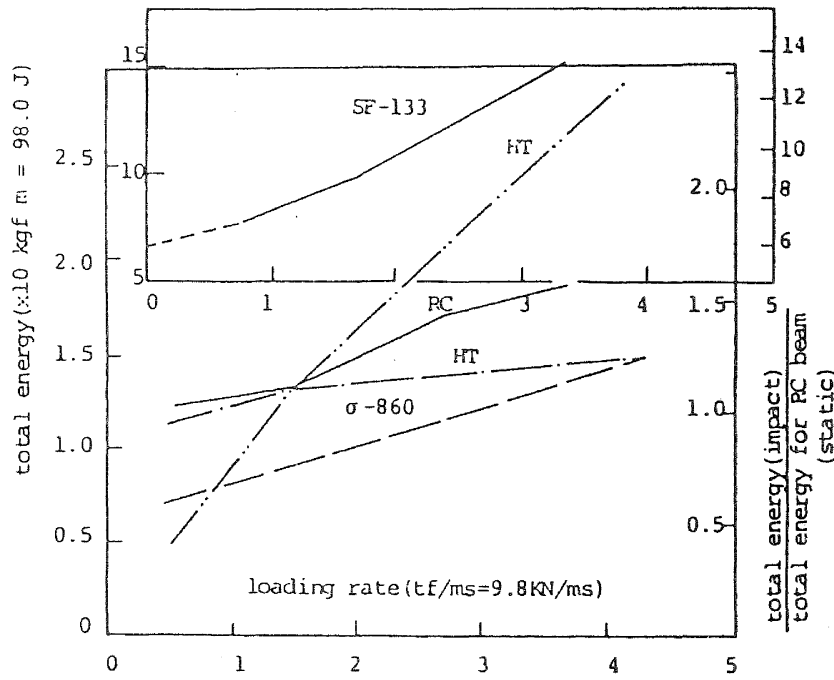

FIGURE 23 : EFFECT OF LOADING RATE ON TOTAL ENERGY 
rate relation. In other words, comparisons can be carried out using the curve gradient in Fig. 21. Table 2 shows the average

\section{TABLE 2 : INCREASING RATE OF LOAD FAILURE}

\begin{tabular}{lc}
\hline Specimen & $\begin{array}{l}\text { Gradient } \\
\left(\mathrm{tf} / \mathrm{tf}^{-1}\right)\end{array}$ \\
\hline $\mathrm{RC}$ & 1.64 \\
\hline $\mathrm{HT}$ & 2.52 \\
\hline $\mathrm{h}-18$ & 1.29 \\
\hline$\sigma-860$ & 1.39 \\
\hline $\mathrm{SF}-133$ & 38.7 \\
\hline
\end{tabular}

gradient of the curves. SF-133 shows a larger degree of sensitivity compared to the other beams and it can be concluded that introduction of steel fibre causes an improvement in load resistance. This value is about 2 to 5 times that of static loading at failure. Improvement of impact resistance can be expected with steel fibre reinforcement. When high yield strength steel is used, improvement in load capacity can be expected at high loading rates.

(b) Deformation abilicy

Fig. 22 shows the deflection at failureloading rate relation. Except for the HT beam, deflection at failure decreases with the increase in loading rate. Comparison can be done by comparing the gradient lines. The RC beam has the largest gradient and it is the most sensitive to the loading rate followed by the $h-18$ beam. The $\sigma-860$ and $\mathrm{SF}-133$ beams do not show a drop in the deformation capability. But for the HT beams, the deformation ability increases with the loading rate. It can be said that the $\mathrm{RC}$ beam is easily affected by changing any of the factors considered. Looking at the effects of these factors, deflection at failure of the SF-133 beam is about 3 times that of the RC beam under static loading thus making it the most effective. For the $\mathrm{HT}$ beam, it can be noticed that for $\mathrm{V}_{\mathrm{I}}=19.6$ $\mathrm{kN} / \mathrm{ms}(2.0 \mathrm{ts} / \mathrm{ms})$ and above, deflection failure is greater than that of RC beams, thus proving its effectiveness. On the other hand, $h-18$ and $\sigma-860$ beams have a smaller deflection at failure, especially the latter which stabilizes at a low value and hence showing a different behaviour from RC beams at low loading rates.

\section{(c) Total energy}

Fig. 23 shows the relations between total energy and loading rates. From the figure, it is clear that the total energy increases as the loading rate is increased. Since total energy is defined as the amount of energy required for beam failure under a single impact, it is roughly equivalent to the energy absorbed by the member. Generally, a change in failure load and also in deflection at failure on the load-deflection hysteresis would cause the amount of total energy to change too. Therefore, evaluating impact resistance by means of the total energy is actually a combination of two independent evaluations, that is evaluation according to the load capacity and also by the deformation ability. Referring to Fig. 23, it can be seen that comparatively, the total energy for the $\mathrm{SF}-133$ beam is large due to the addition of steel fibre as it causes ductility to increase tremendously. For the SF-3 beam, the total energy is about 1.05 times that of the $S F-133$ beam ( $v_{L}=$ $14.7 \mathrm{kN} / \mathrm{ms} ; 1.5 \mathrm{tf} / \mathrm{ms}$ ), thus a linear increase in total energy due to an increase in fibre amount cannot be anticipated. Under soft impacts (low loading rates), an increase in beam depth or in concrete strength has little effect on the beam ductility. The total energy for the HT beam is less than that of the RC beam for loading rates below $14.7 \mathrm{kN} / \mathrm{ms}(1.5 \mathrm{tf} / \mathrm{ms})$ while for rates above that, improvement in ductility can be expected.

\section{(d) Investigation of curvature at failure}

As was investigated in the previous section, local deformation tends to occur at failure when subjected to impulsive loads. Curvature at failure $(I / R)$ will be used here to quantitatively study the local deformations. Curvature at failure is affected by the size of deflections occurring so there are cases when a comparison of local deformation with different deflections at failure is impossible. Therefore, there is a need to eliminate the effects of deflections from the curvature at failure. The following index will be used to evaluate local deformations:

Index of local deformation $=$

$$
\frac{\text { curvature at failure }(1 / R)}{\text { deflection at failure }\left(\delta_{u}\right)}
$$

Table 3 shows the index values for the various beams. To relatively evaluate local deformation, the value for the RC beam with local deformation during static loading is used as a reference value. Fig. 24 shows the index of local deformation-loading rate relation. Increasing the concrete strength results in a large index when compared with the RC beam. Besides that, an increase in crack width and also scabbing can be anticipated. Increased depth gives a value between that of the $\sigma-860$ and RC beams, with local deformations becoming more sensitive towards loading rates. But as the loading rate increases, the values draw close to those of the $0-860$ beams. A stable low index value is obtained in the case of steel fibre reinforced beams, giving the conclusion that local deformations under impact has been greatly improved.

For $\mathrm{v}_{\mathrm{L}}=14.7 \mathrm{kN} / \mathrm{ms}(1.5 \mathrm{tf} / \mathrm{ms})$, the index for $\mathrm{SF}-3$ is 0.96 times that of $\mathrm{SF}-133$. Not much difference can be observed when the fibre content is altered. Usage of high yield strength steel when $v_{L}$ is less than $9.8 \mathrm{kN}$ $/ \mathrm{ms}(1.0 \mathrm{tf} / \mathrm{ms})$ results in quite large local deformations but for values of $v_{T}=14.7 \mathrm{kN} / \mathrm{ms}$ $(1.5 \mathrm{tf} / \mathrm{ms})$ and above, the effects are quite similar to those of SF-133 beams, thus showing a great improvement towards local deformation. 
TABLE 3 : INDEX OF LOCAL DEFORMATION

\begin{tabular}{|c|c|c|c|c|}
\hline Specimen & $\begin{array}{l}\text { Loading } \\
\text { rate } \\
\mathrm{tf} / \mathrm{ms}) \\
(\mathrm{KN} / \mathrm{ms})\end{array}$ & $\begin{array}{c}\text { Curvature } \\
\text { at } \\
\text { failure } \\
\left(\times 10^{-5} / \mathrm{mm}\right)\end{array}$ & $\begin{array}{l}\text { Index of } \\
\text { local } \\
\text { deformation } \\
L_{L}\left(x 10^{-5}\right)\end{array}$ & $\frac{\mathrm{L}_{\mathrm{L}}(\text { impact })}{\mathrm{L}_{\mathrm{L}}}$ \\
\hline \multirow{4}{*}{$\mathrm{RC}$} & $3.8(37.2)$ & 5.15 & 2.13 & 2.39 \\
\hline & $1.5(14.7)$ & 5.25 & 1.60 & 1.80 \\
\hline & $0.5(4.9)$ & 4.63 & 1.13 & 1.27 \\
\hline & static & 4.00 & 0.89 & 1.00 \\
\hline \multirow{3}{*}{$\sigma-860$} & $4.3(42.1)$ & 6.85 & 3.53 & 3.97 \\
\hline & $1.5(14.7)$ & 6.63 & 3.22 & 3.62 \\
\hline & $0.5(4.9)$ & 6.02 & 1.80 & 2.02 \\
\hline \multirow{3}{*}{$n-18$} & $4.3(42.1)$ & 7.23 & 3.56 & 4.00 \\
\hline & $1.5(14.7)$ & 6.51 & 2.31 & 2.60 \\
\hline & $0.5(4.9)$ & 6.00 & 1.70 & 1.91 \\
\hline \multirow{3}{*}{$\mathrm{HT}$} & $4.0(39.2)$ & 3.91 & 1.20 & 1.35 \\
\hline & $1.5(14.7)$ & 3.97 & 1.37 & 1.54 \\
\hline & $0.5(4.9)$ & 5.62 & 2.84 & 3.19 \\
\hline \multirow{4}{*}{$S F-133$} & $3.3(32.3)$ & 16.50 & 1.28 & 1.44 \\
\hline & $1.5(14.7)$ & 17.25 & 1.32 & 1.35 \\
\hline & $0.7(6.9)$ & 16.75 & 1.31 & 1.47 \\
\hline & static & 16.85 & 1.30 & 1.46 \\
\hline \multirow{2}{*}{$S F-3$} & $1.5(14.7)$ & 17.37 & 1.15 & 1.29 \\
\hline & static & 16.82 & 1.11 & 1.25 \\
\hline
\end{tabular}

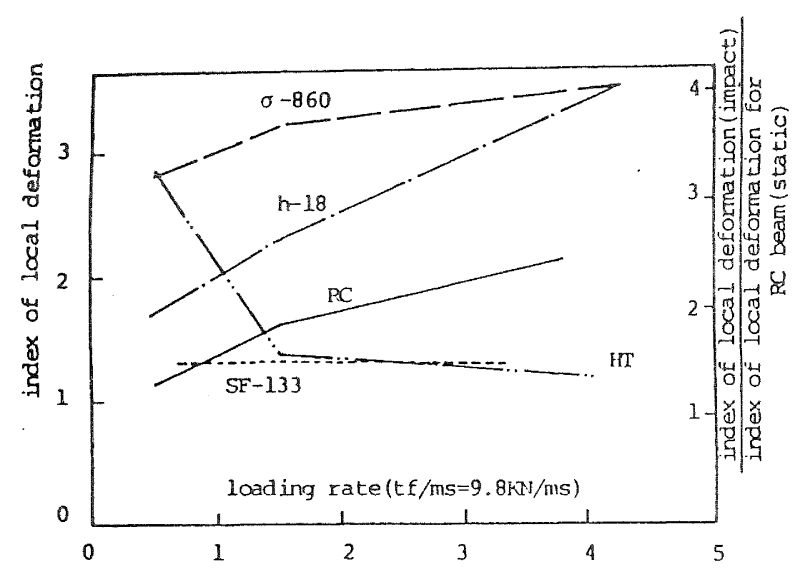

FIGURE 24 : EFFECT OF LOADING RATE ON INDEX OF LOCAL DEFORMATION

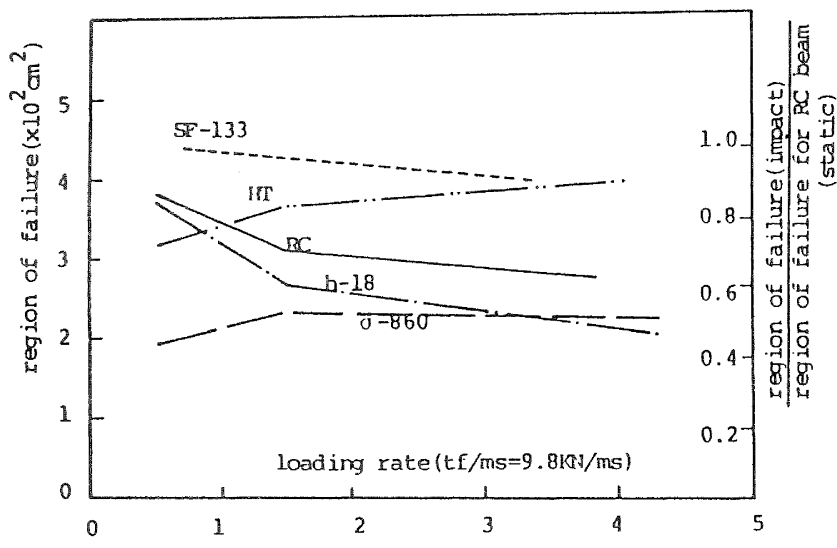

FIGURE 25 : EFFECT OF LOADING RATE CN REGION OF FAILURE 
(e) Examination of failure recion

As mentioned earlier, the failure region is affected by inertia and the area tends to be smaller during impulsive loading. Failure region is the area where the internal energy is released and when the area is small, the cracks will be large and failure condition gets bad. The failure region will be treated numerically, thus allowing failure conditions to be analytically studied. Sketches of crack conditions at failure for all types of beams were examined and the area of failure was calculated. The values are indicated in Table 4 and the relation with regard to the loading rate is shown in Fig. 25. For high yield strength steel, the failure region is smaller that that of $\mathrm{RC}$ beams at rates of $\mathrm{v}_{\mathrm{L}}=9.8 \mathrm{kN} / \mathrm{ms}$ $(1.0 t f / m s)$ and below but at higher rates, failure condition is markedly improved. SF-133 has larger values than that of RC beams on the whole. Therefore, it can be concluded that an addition of steel fibre reinforcement is effective in improving failure conditions.

\section{Design Criteria}

Impact designs for most structures are carriea out by adopting an impact factor in the static design method. The dynamic force during impact is converted into a static force of equal magnjtude and treated in much the same way as other static loads. This static design method would not adequately describe an impact phenomenon and thus have only a limited amount of practical applicability. During impacts, an excitation of not only the first mode but also higher modes can be expected. Structures designed using the equivalent static force would be able to withstand bending but not the shear, hence bringing about punching shear or concrete scabbing. These factors can only be totally considered if a dynamic design approach is adopted.

Two main concepts shall be considered in the designing of $\mathrm{RC}$ beams under impulsive loading. The first concept is to design the beams to withstand high mode excitations. RC beams in this case usually experience shear failure. Shear failure can be minimized by increasing the shear strength at midspan by introducing adequate lateral reinforcement. The other concept is to design the beams so that energy can be easily absorbed during impacts. Improper energy absorption brings about not only concrete scabbing but also a greater degree of damage to both of the colliding bodies. This is mainly caused by a lack of deformation ability in the structures. Improving the deformation ability, or in other words the total energy, helps the beams withstand impulsive loads.

As seen in the previous section, steel fibre has the ability to absorb energy as well as increase the deformation capability tremendously. Moreover, it can also control cracking, thus improving the ductility of concrete. High yield strength steel helps out too as it shows improvement in load capacity and deformation ability together with some restriction in failure region.
TABLE 4: REGION OF FAILURE

\begin{tabular}{|c|c|c|c|}
\hline Specimen & $\begin{array}{l}\text { Loading } \\
\text { rate } \\
\mathrm{tf} / \mathrm{ms} \\
(\mathrm{KN} / \mathrm{ms})\end{array}$ & $\begin{array}{l}\text { Region } \\
\text { of } \\
\text { failure } \\
A_{f}\left(\mathrm{~cm}^{2}\right)\end{array}$ & $\frac{A_{f}(\text { impact })}{A_{f}(\text { sitatic })}$ \\
\hline \multirow{4}{*}{$\mathrm{RC}$} & $3.8(37.2)$ & 278 & 0.62 \\
\hline & $1.5(14.7)$ & 310 & 0.70 \\
\hline & $0.5(4.9)$ & 380 & 0.85 \\
\hline & static & 445 & 1.00 \\
\hline \multirow{3}{*}{$\sigma-860$} & $4.3(42.1)$ & 228 & 0.51 \\
\hline & $1.5(14.7)$ & 230 & 0.52 \\
\hline & $0.5(4.9)$ & 190 & 0.43 \\
\hline \multirow{3}{*}{$h-18$} & $4.3(42.1)$ & 208 & 0.47 \\
\hline & $1.5(14.7)$ & 265 & 0.60 \\
\hline & $0.5(4.9)$ & 365 & 0.82 \\
\hline \multirow{3}{*}{$\mathrm{HT}$} & $4.0(39.2)$ & 400 & 0.90 \\
\hline & $1.5(14.7)$ & 365 & 0.82 \\
\hline & $0.5(4.9)$ & 318 & 0.71 \\
\hline \multirow{4}{*}{$S F-133$} & $3.3(32.3)$ & 403 & 0.87 \\
\hline & $1.5(14.7)$ & 425 & 0.91 \\
\hline & $0.7(6.9)$ & 440 & 0.99 \\
\hline & static & 525 & 1.18 \\
\hline \multirow{2}{*}{$S F-3$} & $1.5(14.7)$ & 608 & 1.37 \\
\hline & static & 653 & 1.46 \\
\hline
\end{tabular}

\section{CONCLUSIONS}

The results obtained from this study can be summed up as such:

(1) Comparison between the calculations and the experiment results show that this analysis is of relatively high accuracy.

(2) The dynamic characteristics of RC beams under impacts can be described as follows: increase in load capacity, drop in deflection capability, increase in local deformation and decrease in failure region. These characteristics tend to increase under high loading rates.

(3) Based on the behaviour of RC beams under impact, a logical assessment of impact resistance can be carried out based on the following items:

i) Degree of improvement of load capacity.

ii) Degree of suppression of drop in deformation capability at failure.

iii) Degree of suppression of drop in toughness.

iv) Degree of suppression of critical local deformation.

v) Degree of suppression of increase in failure region.

(4) The following indexes can be utilized for evaluating impact resistance: load capacity, deformation capability, total energy, curvature at failure and failure region. 
(5) The improvement of ultimate tensile strain in concrete by means of steel fibre reinforcements etc., is the most effective solution for impact resistance.

(6) The usage of high yield strength steel as reinforcement is effective for impacts with high loading rates.

(7) Increasing beam depth can cause a drop in impact resistance.

(8) Increasing only the concrete strength could decrease impact resistance. This can be overcome by improving the ultimate

tensile strain for high strength concrete.

\section{REFERENCES}

1. Bathe, K.J, and Wilson, E.L., 1976. Numerical methods in finite element analysis, Prentice-Hall, Inc. New Jersey.

2. Hannant, D.J., 1978, Fibre cements and fibre concrete, John Wiley \& Sons, Ltd. Sussex, England.

3. Hughes, G. and Beeby, A.W., Sept. 1982. Investigation of the effect of impact loading on concrete beams, The structural Engineer 60B(3): 45-52.

4. Isobata, O., Nov, 1971. Two-dimensional elastic-plastic analysis of concrete structure by the finite element method, Architectural Institute of Japan 189(11): 43-50.

5. Koyanagi, W., Rokugo, K. et aI. 1983. Energy approach to deformation and fracture of concrete under impact load, Japan Concrete Institute 5th Conference: 129-132.

6. Fujii, M., Miyamoto, A. et al. Aug. 1985. An analytical study on the behaviour of reinforced concrete beams under impulsive load, Proceedings of Japan Society of Civil Engineers 360 $(V-3): 51-60$.

7. Fujii, M., Miyamoto, A. et al. 1987. Analysis of nonlinear behaviour of reinforced concrete slabs under impulsive load, Proceedings of the Japan Concrete Institute 9(2): 609-614.

8. Fujii, M., Miyamoto, A. et al. 1985. Dynamic non-linear modelling of reinforced concrete beams under impulsive loads, Japan Concrete Institute 7 th Conference: $349-352$.

9. Fujii, M., Miyamoto, A. et al. 1981. Failure mechanism of SFRC slabs under impact loading, Japan Concrete Institute 3rd Conference: 197-200.

10. Suaris, W. et al. April 1982. Strainrate effects in fibre-reinforced concrete subjected to impact and impulsive loading. Composite : 153-159. 